\title{
Weight loss in individuals with metabolic syndrome given DASH diet counseling when provided a low sodium vegetable juice: a randomized controlled trial
}

Sonia F Shenoy ${ }^{1 *}$, Walker SC Poston ${ }^{2}$, Rebecca S Reeves ${ }^{3}$, Alexandra G Kazaks ${ }^{4}$, Roberta R Holt ${ }^{1}$, Carl L Keen ${ }^{1,5}$, Hsin Ju Chen ${ }^{1}$, C Keith Haddock ${ }^{2}$, Barbara L Winters ${ }^{6}$, Chor San H Khoo ${ }^{6}$, John P Foreyt ${ }^{3}$

\begin{abstract}
Background: Metabolic syndrome, a constellation of metabolic risk factors for type 2 diabetes and cardiovascular disease, is one of the fastest growing disease entities in the world. Weight loss is thought to be a key to improving all aspects of metabolic syndrome. Research studies have suggested benefits from diets rich in vegetables and fruits in helping individuals reach and achieve healthy weights.
\end{abstract}

Objective: To evaluate the effects of a ready to serve vegetable juice as part of a calorie-appropriate Dietary Approaches to Stop Hypertension (DASH) diet in an ethnically diverse population of people with Metabolic Syndrome on weight loss and their ability to meet vegetable intake recommendations, and on their clinical characteristics of metabolic syndrome (waist circumference, triglycerides, HDL, fasting blood glucose and blood pressure).

A secondary goal was to examine the impact of the vegetable juice on associated parameters, including leptin, vascular adhesion markers, and markers of the oxidative defense system and of oxidative stress.

Methods: A prospective 12 week, 3 group (0, 8, or 16 fluid ounces of low sodium vegetable juice) parallel arm randomized controlled trial. Participants were requested to limit their calorie intake to $1600 \mathrm{kcals}$ for women and 1800 kcals for men and were educated on the DASH diet. A total of 81 (22 men \& 59 women) participants with Metabolic Syndrome were enrolled into the study. Dietary nutrient and vegetable intake, weight, height, leptin, metabolic syndrome clinical characteristics and related markers of endothelial and cardiovascular health were measured at baseline, 6-, and 12-weeks.

Results: There were significant group by time interactions when aggregating both groups consuming vegetable juice (8 or 16 fluid ounces daily). Those consuming juice lost more weight, consumed more Vitamin C, potassium, and dietary vegetables than individuals who were in the group that only received diet counseling $(p<0.05)$.

Conclusion: The incorporation of vegetable juice into the daily diet can be a simple and effective way to increase the number of daily vegetable servings. Data from this study also suggest the potential of using a low sodium vegetable juice in conjunction with a calorie restricted diet to aid in weight loss in overweight individuals with metabolic syndrome.

\footnotetext{
* Correspondence: sfshenoy@ucdavis.edu

${ }^{1}$ Department of Nutrition, University of California, Davis, USA
}

C 2010 Shenoy et al; licensee BioMed Central Ltd. This is an Open Access article distributed under the terms of the Creative Commons 


\section{Background}

Metabolic syndrome, a constellation of metabolic risk factors for type 2 diabetes and cardiovascular disease, is one of the fastest growing disease entities in the world $[1,2]$; as an example in the United States it is thought to affect over $30 \%$ of adults [3]. Weight loss is thought to be a key to improving all aspects of metabolic syndrome [4]. Research studies have suggested a number of benefits of diets rich in vegetables and fruits in helping individuals reach and achieve healthy weights [5]. Vegetables and fruits, which are typically low in calories, can provide an abundance of essential nutrients and health promoting phytochemicals [6]. Clinical science and public health data underscore the potential health benefits that could be realized if vegetable intakes matched current dietary recommendations [7]. Regrettably, adopting and maintaining a healthy lifestyle, including a diet rich in vegetables, fruits, lean meats and low fat dairy products, seems to be problematic for many individuals, even when they are aware of its benefits [8]. For example, McGee et al. reported that focus group participants from the Lower Mississippi Delta with chronic disease risk factors resisted adopting a healthy diet, when it meant giving up traditional or culturerelated dietary habits [9]. Data show that older ethnic minorities do not meet the minimum recommendations for vegetables and fruits [10]. Preparation time [9], price [11], taste [12], and lack of convenience [13] are among barriers that have been reported to contribute to the low consumption of vegetables and fruits.

Research on the favorable effects of vegetables and fruits and their phytochemicals is expanding rapidly with data showing positive impacts of many plant foods on risk factors for chronic diseases [14]. Specific to metabolic syndrome, diets high in vegetables have been reported to have beneficial effects with respect to fasting blood glucose, dyslipidemia, and hypertension [15-18]. While it could be argued that the above positive effects of high vegetable diets may simply reflect the adoption of "healthy diets," there is increasing evidence that some of the reported positive effects may be linked to specific phytochemicals. For example, it has been reported that carotenoids can inhibit damage and thickening of the arterial wall, possibly due to their ability to lower the production of select inflammatory cytokines [19]. Similarly, data with an inverse association of plasma lycopene levels and intima thickening, one index of cardiovascular disease [20] has been reported. Two different double-blind, placebo-controlled trials, showed a tomato extract significantly reduced systolic and diastolic blood pressure; one study had patients with grade 1 hypertension [21], and another with moderate hypertension despite anti-hyptertensive medication at enrollment
[22]. In another study, beneficial results on platelet function were reported in healthy volunteers after drinking a tomato extract $[23,24]$. Research is increasing not only on the individual phytochemicals, but also on their potential synergistic health benefits [25].

The primary goal of the present research was to examine the effects of consuming 8 or 16 fluid ounces of low sodium vegetable juice as part of a calorie-appropriate Dietary Approaches to Stop Hypertension (DASH) diet in an ethnically diverse population on the ability of vegetable juice to help subjects lose weight, meet their recommended vegetable intake, and on clinical characteristics of metabolic syndrome (waist circumference, triglycerides, HDL, fasting blood glucose and blood pressure). A secondary goal was to examine the impact of the incorporation of vegetable juice in the diet on associated parameters, including leptin, vascular adhesion markers, and markers of the oxidative defense system and oxidative stress.

\section{Methods}

\section{Study Population and Setting}

Adult men and women, ages 35-65, were recruited from the Houston, TX community using advertisements placed on several key radio stations, in local neighborhood and business newspapers, free newspapers containing advertising, and the Baylor College of Medicine health newsletter. Two hundred and fifty-three individuals were screened in the clinic and 81 (59 women and 22 men) met inclusionary criteria and were randomized into the study. Those who responded to our advertisements and met the clinical criteria tended to be minorities. Specifically, the participants included: $57 \%$ AfricanAmerican, 23\% Mexican American, 17\% Caucasian, and $4 \%$ other.

Participants enrolled into the study met the criteria set by the National Cholesterol Education Program (NCEP) Adult Treatment Panel (ATP) Panel III for metabolic syndrome defined as meeting at least three out of the five following parameters: 1) waist circumference for men $>40$ in, for women $>35$ in; 2) triglycerides $>150$ $\mathrm{mg} / \mathrm{dl}$; 3) systolic blood pressure $>130 \mathrm{~mm} \mathrm{Hg}$ or diastolic blood pressure $>85 \mathrm{~mm} \mathrm{Hg}$; 4) fasting blood glucose $>100 \mathrm{mg} / \mathrm{dl}$; 5) HDL-cholesterol $<40 \mathrm{mg} / \mathrm{dl}$ for men and $<50 \mathrm{mg} / \mathrm{dl}$ for females. Body mass indices (BMIs) of the eligible participants could range from 30$50 \mathrm{~kg} / \mathrm{m}^{2}$.

Participants were excluded from the study for the following reasons: use of anxiolytics or antidepressive medication, hormone replacement therapy, reported alcohol consumption in excess of 1 fluid ounce/day, diabetes controlled with insulin, hyper- or hypothyrodism, inflammatory disorders, treatment with corticosteroids 
and anti-inflammatory drugs, routine use of aspirin and other NSAIDs, or a history of a major cardiovascular event. The following clinical parameters were exclusionary: abnormal complete blood cell count defined as low/ high WBCs (less than $4.0 \mathrm{~K} / \mathrm{mm}^{3}$ or greater than 11.0 $\mathrm{K} / \mathrm{mm}^{3}$ ), hemoglobin (less than 11.5 or greater than $17.0 \mathrm{~g} / \mathrm{dL}$ ), platelets (less than $130 \mathrm{~K} / \mathrm{mm}^{3}$ or greater than $450 \mathrm{~K} / \mathrm{mm}^{3}$ ), or a Beck Depression Inventory ${ }^{\circ}$ (BDI) scale score of 21 or above (Pearson Education, Inc., San Antonio, Texas). With the exception of basic multivitamin/mineral supplements, subjects were instructed to refrain from using dietary supplements, including herbs and omega- 3 fatty acids during the study period. Participants were instructed to refrain from using nonsteroidal and anti-inflammatory medications for the week prior to a clinic visit. All subjects provided written informed consent at the time of screening, and the Institutional Review Board at Baylor College of Medicine approved this study.

\section{Study Design}

Eligible subjects were randomized into one of three groups: (1) 8 fluid ounces of low sodium vegetable juice/day; (2) 16 fluid ounces of low sodium vegetable juice/day; or (3) no vegetable juice/day, for a 12-week period. Clinic visits were at baseline (week 0), week 6 and week 12 of the study. Subjects were instructed to follow a low carotenoid diet for the week prior to the baseline visit and a low flavonoid diet 24 hours prior to all visits. Previous studies suggest that these dietary phytochemicals can have a positive impact on vascular function $[26,27]$. Three day diet records were collected prior to the low carotenoid washout diet at baseline and prior to the 24 hour low flavonoid diet at the 6 and 12 week visits.

All participants were asked to follow a calorie-controlled DASH diet plan. Men were asked to follow an $1800 \mathrm{kcal}$ diet and women a $1600 \mathrm{kcal}$ diet. DASH is an eating pattern recommended by the 2005 Department of Health and Human Services Dietary Guidelines for Americans as a model of healthy eating for the majority of individuals in the population [28]. The DASH diet emphasizes vegetables, fruits, whole grains, lean meats and low fat dairy foods, and is rich in magnesium, potassium, calcium and fiber [29]. At the baseline visit following randomization to one of three groups, all participants spent about 45 minutes with a dietitian learning the basics of the DASH diet. Dietitians emphasized the following points of the nutrition education material to participants:

1. Key aspects of the DASH eating plan placing emphasis on vegetables and fruits.

2. Appropriate serving sizes of foods.
3. Realistic personal goals and meal plans.

4. Tips to make healthy eating easier.

5. Checklist to track their individual progress towards meeting the DASH goals.

A notebook containing relevant DASH nutrition education material was provided to participants. At the 6 week visit, a brief follow-up session was again conducted with dietitians who asked about progress in following the diet.

Participants randomly assigned to the beverage groups were supplied with the low sodium vegetable juice for each 6 week period. The juice was packaged in 46ounce bottles with a plain black and white label. The same manufacturing lot was used for all subjects for the 12 -week study period. A clear plastic glass with an 8 fluid ounce marker was provided for ease of juice measurement. Eight fluid ounces of the low sodium vegetable juice (V8 ${ }^{\circ}$; Campbell Soup Company, Camden NJ) provided 50 calories, $0 \mathrm{~g}$ of total fat and cholesterol, 140 $\mathrm{mg}$ of sodium, $820 \mathrm{mg}$ of potassium, $2 \mathrm{~g}$ of protein, 20 $\mathrm{mg}$ lycopene, and $10 \mathrm{~g}$ of total carbohydrate of which 2 g were dietary fiber. The juice provided $40 \%$ of the Daily Value of Vitamin A from naturally occurring betacarotene in the vegetables (1000 IUs $=300$ micrograms RAEs (Retinol Activity Equivalents)), 120\% of Vitamin $\mathrm{C}$, and $2 \%$ of calcium and iron.

\section{Data Collection and Measures}

General health, medication use and lifestyle characteristics were assessed at baseline. At weeks 6 and 12, subjects who consumed 8 or 16 fluid ounces of juice/day completed an 8-item Beverage Consumption Questionnaire that included questions about the perceived taste and health benefits of the beverage. Daily beverage consumption was reported on checklists to measure adherence to their allotted juice group protocol. Similar to the literature, subjects were deemed highly adherent to the protocol if they consumed their allotted amount of juice at least $85 \%$ of the study days ( 72 of the 84 days of the trial) [30,31]. Three-day food records were collected from 2 weekdays and 1 weekend day before study visits at baseline, week 6 and week 12. The food records were reviewed by a registered dietitian when they were submitted and then were sent to the University of California, Davis where a registered dietitian supervised duplicate data entry and analysis using Food Processor software (Version 10.2.0, ESHA research, Inc., Salem, OR). Vegetable servings were quantified according to MyPyramid cup servings [32].

Clinical measurements included blood pressure, weight, height, and waist circumference. Blood pressure measurements were the average of 2 measurements and were taken using an automated system (Dinamap Pro 
100 by GE, Criticon, Tampa, FL.) after the subjects were seated for 5 minutes. For weight and height measurements, subjects were fully dressed, with the exception that their shoes were removed. Height was recorded on their first visit using a wall-mounted stadiometer (Accustat Genentech, San Francisco, CA). Weight was recorded every visit using an electronic scale (Tanita, BWB-800. Tokyo, Japan.). Body mass index $\left(\mathrm{kg} / \mathrm{m}^{2}\right)$ was calculated as weight $(\mathrm{kg})$ divided by height squared $\left(\mathrm{m}^{2}\right)$.

At the screening visit, blood samples were drawn for the comprehensive metabolic panel (chemistry, lipid, fasting blood glucose, liver function and complete blood count) and analyzed at the Clinical Pathology Laboratory in Austin, TX. At baseline, 6 and 12 weeks, blood samples for lipids, high sensitivity $\mathrm{C}$-reactive protein (hsCRP), glycated hemoglobin (HgAlc) and insulin were analyzed at the Atherosclerosis Clinical Research Laboratory, a core laboratory in the Department of Medicine at Baylor College of Medicine. Plasma was collected for the measurement of adhesion markers, leptin, and for plasma indicators of oxidant defense (total reactive antioxidant potential (TRAP)) and oxidative damage (thiobarbituric acid reactive substances (TBARS)). TRAP and TBARS were analyzed as previously described [33].

Leptin, and vascular adhesion markers (soluble-Intercellular Adhesion Molecule-1, soluble-Vascular Cell Adhesion Molecule-1, soluble P-Selectin, soluble ESelectin), and soluble CD40 ligand were measured using a commercially available enzyme-linked immunosorbent assay (ELISA) kits (leptin, adhesion markers: R\&D Systems, Minneapolis, MN, sCD40L: Bender MedSystems, Burlingame, CA) according to the manufacturer's instructions.

\section{Statistical Approach}

Descriptive data (means, standard deviations) are provided for study outcomes stratified by the three study conditions. For weight change, descriptive data also is presented after applying imputational methods (described below) for modeling missing data.

\section{Changes in Body Weight}

Three different unadjusted statistical models were created to examine the impact of the three study conditions on body weight. The first model examined weight loss among completers of the three treatment conditions. Next, two models which imputed treatment outcome data for participants who dropped out of the study were developed. The first imputational model was based on the Last Observation Carried Forward (LOCF) $[34,35]$ method. The second imputation model used a conservative Intention-to-Treat (ITT) method where missing values are imputed based on average weight gain after dropout of $0.30 \mathrm{~kg} /$ month (or $0.075 \mathrm{~kg} /$ week) after study withdrawal, an approach that has been used successfully in other large clinical trials $[35,36]$ and is even more conservative because it assumes that weight regain can exceed baseline weight. For all three models, General Linear Models for repeated measures were developed where the between-subjects factor was group assignment and the within-subjects factor was body weight at baseline, 6 weeks, and 12 weeks. Data were examined based on a comparison of the results from the three methods for modeling missing data. A multivariate approach was used to test a group by time interaction in each model based on the Wilks Lambda test of significance. The multivariate test was conducted on difference scores, and therefore the assumptions underlying the multivariate test concern these difference scores. Difference scores (change from baseline) for weight outcomes are presented to aid interpretability. LSD and the more conservative Tukey HSD post-hoc comparisons were used for any statistically significant unadjusted model.

\section{Changes in Leptin, Adhesion Markers, CD40L, Blood Pressure, and Food Record Data}

General linear models with repeated measures were used to examine changes in leptin, adhesion markers, blood pressure, and food diary data for the three study conditions. All models are based on participants who completed the study given that imputational approaches for small samples are not well developed for these factors. Tukey post-hoc comparisons were used for any statistically significant unadjusted model.

\section{Adjusted Aggregate Models}

Given the attrition observed in the study, the resultant reduction in statistical power, and the fact that no differences were found between the 8 fluid ounce low sodium vegetable juice and 16 fluid ounce juice conditions on any outcome, the 8 and 16 fluid ounce juice groups were aggregated into a single group and the aggregated condition was compared to the group that did not consume the juice (control group). Thus, aggregate models were developed to compare any low sodium vegetable juice consumption to none. In addition, gender, education, and age were included as covariates in the adjusted models. These covariates were selected because of the relatively large differences in their distribution by group status even though the differences were not statistically significant, as well they were used because have been previously demonstrated to be related to weight loss outcomes [37-39].

Medication use was also examined to assess whether inclusion of a measure of medication use (i.e., number of medications used) enhanced the precision of outcomes models. This was implemented because outcome variables might be affected by prescription and OTC medication use, i.e., weight, leptin, systolic and diastolic blood pressure, and all lipid fractions. Any listed 
substance was excluded that was not clearly a medication (i.e., any nutritional supplement or vitamin). However, clear distinctions between prescription and over the counter (OTC) medications was not possible because some OTC drugs were prescribed (e.g., aspirin) and some participants did not list an actual medication, but instead a class of medications (e.g., "blood pressure medicine" or "allergy pills"). Thus, all OTC and prescription medication were grouped and counted as the total number of medications for each participant. The simplified models with juice consumption aggregated showed that that the addition of frequency of medication use did not substantially improve already significant models and did not change models that were previously not statistically significant.

\section{Results}

A total of 81 individuals participated in the study (27 in each study condition) (Figure 1). Baseline characteristics of the participants were similar among groups (Table 1). Overall retention was $74 \%$ and attrition was similar across groups. None of the baseline characteristics or treatment group status were associated with dropping out of the study.

We observed that $100 \%$ of subjects in the 8 fluid ounce/day group had high rates of adherence (i.e., beverage consumption on $>85 \%$ of days in the study) over the 12 week trial, whereas only $53 \%$ of subjects in the 16 fluid ounce/day group had the same level of adherence.

\section{Weight Loss}

All three models (i.e., completers, LOCF, and conservative ITT) demonstrated that participants in the two vegetable juice groups lost more weight, on average, than the group that did not drink the juice. However, there were no statistically significant group differences in weight loss over time (i.e., group by time interaction) (Table 2). When using adjusted, aggregated models, (vegetable juice vs. no vegetable juice) the group by time interaction tests for weight were statistically significant for completers $(\mathrm{F}=4.3, \mathrm{p}=0.02$; data not shown $)$ and the LOCF and ITT models $(\mathrm{F}=3.8, \mathrm{p}=0.03$ for both; data not shown), indicating that participants who consumed one or more servings of vegetable juice experienced significantly more weight loss than those who did not consume the juice.

\section{Leptin}

Both unadjusted and adjusted statistical models were created to examine the impact of the three study conditions on leptin. Table 3 presents changes in leptin by group status over the 12-week trial. The unadjusted model for leptin was statistically significant between the groups over the 12 week study period $(\mathrm{F}=3.4, \mathrm{p}=$ $0.01)$. Similarly, in the adjusted model of aggregated vegetable juice groups, there was a significant group by time interaction for leptin (Table 3; F = 3.4, $\mathrm{p}=0.04$ ) that paralleled weight loss. Additionally, post-hoc paired t-tests comparing baseline levels to both 6- and 12-week only showed significant changes in those consuming 8 fluid ounces of vegetable juice (respectively, $\mathrm{t}=2.578$, $\mathrm{p}=0.02 ; \mathrm{t}=3.767, \mathrm{p}=0.002$ ).

\section{Blood Pressure and Plasma Measurements}

Systolic or diastolic blood pressure was not statistically significantly changed (data not presented) between groups over the 12 week study period. No significant differences were observed in the markers of oxidant defense or oxidative stress (TRAP and TBARS respectively) that were assessed in the study (data not presented). No significant differences were observed in any of the vascular adhesion markers, hsCRP, HgAlc, and sCD40L (data not shown).

\section{Food Records Data}

Table 4 presents food record data of selected nutrients for completers stratified by treatment condition. Table 5 shows vegetables intake by cups, in accordance with the MyPyramid definition [32], and by study treatment group, first with counting the vegetable juice followed by without vegetable juice as part of the sum of vegetable intake. Unadjusted General Linear Models examining group by time interactions among completers for food records were first computed. As shown in Tables 4 and 5, groups consuming vegetable juice increased their intake of vitamin $\mathrm{C}(\mathrm{F}=6.5, \mathrm{p}<0.001)$, potassium $(\mathrm{F}=$ $3.9, \mathrm{p}<0.002)$, and vegetables $(\mathrm{F}=4.3, \mathrm{p}=0.003)$ over time compared to those who did not consume juice.

Vitamin C post-hoc analyses revealed that intakes were significantly higher in the 16 fluid ounce/day group than in the 8 fluid ounces/day group $(\mathrm{p}=0.002$ and 0.005 for LSD and Tukey HSD, respectively). Vitamin $C$ intakes were also higher in the 16 fluid ounce/ day group versus the group not consuming any juice ( $\mathrm{p}<0.001$ for both LSD and Tukey HSD). Using the LSD test, those who drank 8 fluid ounces/day of vegetable juice reported higher vitamin $C$ intakes than those who did not drink the juice $(\mathrm{p}=0.03)$. However, the difference between the 8 fluid ounces/day vegetable juice and no vegetable juice group was not significant using the Tukey HSD ( $\mathrm{p}=0.07)$.

With respect to potassium, post-hoc analyses showed those who consumed 16 fluid ounces/day vegetable juice reported higher intake relative to the 8 fluid ounces/day group ( $\mathrm{p}=0.001$ and 0.004 for LSD and Tukey HSD, respectively). Those who consumed no vegetable juice had significantly lower intakes of potassium than those 


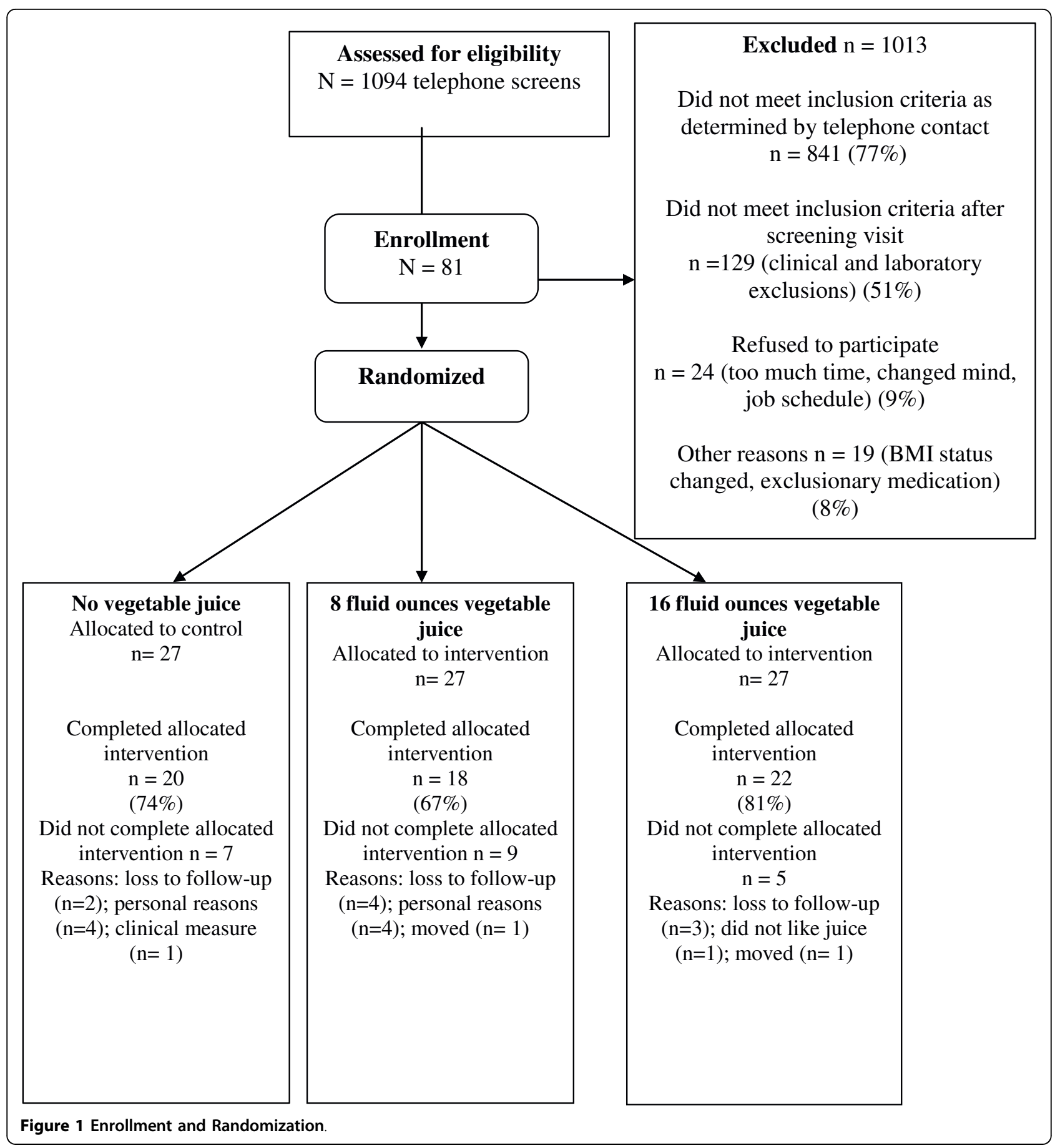

consuming 16 fluid ounces of juice $(\mathrm{p}<0.001$ for both LSD and Tukey HSD). The difference between the 8 fluid ounces/day vegetable juice and the no juice group was not statistically significant for either post-hoc test ( $\mathrm{p}=0.06$ and 0.13 for LSD and Tukey HSD, respectively).

Post-hoc analyses of vegetable intake using the MyPyramid vegetable definition illustrated those who did not incorporate the vegetable juice into their diet reported significantly less vegetable intake than those who consumed 8 fluid ounces/day of vegetable juice $(p=0.002$ and $<0.001$ for LSD and Tukey HSD, respectively); the difference between the 8 fluid ounce/day and 16 fluid ounce/day juice groups was non-significant $(\mathrm{p}=0.40$ and 0.68 for LSD and Tukey HSD, respectively).

Given study attrition, the adjusted and aggregated models were computed. These data showed significant 
Table 1 Participant Characteristics by Group Assignment (Mean or \%, SD)

\begin{tabular}{|c|c|c|c|c|}
\hline \multirow[b]{2}{*}{ Demographic and Clinical Characteristics } & \multicolumn{4}{|c|}{ Group Assignment } \\
\hline & $\begin{array}{l}\text { No Vegetable } \\
\text { Juice }\end{array}$ & $\begin{array}{c}8 \text { fluid ounces Vegetable } \\
\text { Juice } \\
\text { Per Day }\end{array}$ & $\begin{array}{l}16 \text { fluid ounces } \\
\text { Vegetable Juice } \\
\text { Per Day }\end{array}$ & $\begin{array}{c}\text { All } \\
\text { Participants }\end{array}$ \\
\hline Female* $(\%)$ & 74.1 & 85.2 & 59.3 & 72.8 \\
\hline \multicolumn{5}{|l|}{ Ethnicity (\%) } \\
\hline -White & 19.2 & 15.4 & 14.8 & 16.5 \\
\hline -African-American & 50.0 & 57.7 & 63.0 & 57.0 \\
\hline -Mexican-American & 30.8 & 23.1 & 14.8 & 22.8 \\
\hline -Other & 0.0 & 3.8 & 7.4 & 3.7 \\
\hline Education: High School or Less (\%) & 56.0 & 62.5 & 58.3 & 58.9 \\
\hline Current Smoker (\%) & 14.8 & 14.8 & 11.5 & 13.3 \\
\hline Age (Years) & $50.1(5.1)$ & $51.2(7.4)$ & $48.0(7.7)$ & $49.8(6.9)$ \\
\hline Baseline Weight (kg) & $104.2(18.1)$ & $100.2(17.6)$ & $112.4(18.1)$ & $105.6(18.4$ \\
\hline Baseline BMI & $37.8(4.6)$ & $37.3(5.3)$ & $38.3(4.9)$ & $37.8(4.9)$ \\
\hline Baseline Waist Circumference $(\mathrm{cm})$ & $115.3(13.3)$ & $112.9(10.5)$ & $119.1(15.2)$ & $115.8(13.3)$ \\
\hline Baseline Systolic Blood Pressure (mmHg) & $132.8(20.9)$ & $134.5(20.6)$ & $124.4(15.3)$ & $130.6(19.4)$ \\
\hline Baseline Diastolic Blood Pressure (mmHg) & $84.8(11.8)$ & $83.8(11.5)$ & $80.5(9.9)$ & $83.0(11.1)$ \\
\hline Baseline Medication Use (\#) & $1.7(2.0)$ & $1.8(2.2)$ & $1.0(1.6)$ & $1.5(2.0)$ \\
\hline \multicolumn{5}{|l|}{ Baseline Metabolic Syndrome Criteria (\% with criteria) } \\
\hline $\begin{array}{l}\text { Waist Circumference } \\
(\geq 88 \mathrm{~cm} \text { for women or } \geq 102 \mathrm{~cm} \text { for men; \%) }\end{array}$ & 100.0 & 100.0 & 100.0 & 100.0 \\
\hline $\begin{array}{l}\text { Blood Pressure } \\
\text { (Systolic } \geq 130 \mathrm{mmHg} \text { or Diastolic } \geq 85 \mathrm{mmHg} ; \%)\end{array}$ & 63.0 & 51.9 & 40.7 & 51.9 \\
\hline Triglycerides ( $\geq 150 \mathrm{mg} / \mathrm{dl} ; \%)$ & 37.0 & 25.9 & 23.1 & 28.9 \\
\hline HDL (Men <40 mg/dl or Women <50 mg/dl; \%) & 96.0 & 80.8 & 87.5 & 88.0 \\
\hline Blood Glucose ( $\geq 100$ mg/dl; \%) & 100.0 & 96.3 & 100.0 & 98.7 \\
\hline
\end{tabular}

${ }^{*} \chi^{2}=4.6, p=0.10$

differences over time between the aggregated groups consuming juice compared to the control group for carbohydrates $(F=3.3, p=0.05)$, total sugars $(F=3.3$, $\mathrm{p}=0.05$; data not shown $)$, vitamin $\mathrm{C}(\mathrm{F}=4.6, \mathrm{p}=$ $0.02)$, and potassium $(F=3.9, p=0.03)$. Those consuming vegetable juice significantly reduced their carbohydrate and sugar intake over time compared to those not consuming juice. Additionally, those drinking juice significantly increased their potassium intake over time compared to those not drinking it. Participants consuming vegetable juice experienced large increases over time in vegetable intake relative to the no juice group (see Table 5) using MyPyramid ( $\mathrm{F}=3.6, \mathrm{p}=$ 0.04 ) vegetable categorization method. However, when vegetable juice intake is excluded from being counted in the dietary intake, there were no significant changes

Table 2 Weight Loss (kg; M, SD) Over Time by Group Status for Completers, LOCF, and Conservative ITT Models

\begin{tabular}{|c|c|c|c|c|c|c|}
\hline \multirow{3}{*}{ Weight Loss Marker } & \multicolumn{6}{|c|}{ Treatment Group } \\
\hline & \multicolumn{2}{|c|}{ No Vegetable Juice } & \multicolumn{2}{|c|}{8 fluid ounces Vegetable Juice } & \multicolumn{2}{|c|}{16 fluid ounces Vegetable Juice } \\
\hline & 6 Weeks & 12 Weeks & 6 Weeks & 12 Weeks & 6 Weeks & 12 Weeks \\
\hline Completers (kg) N & 19 & 20 & 18 & 18 & 23 & 22 \\
\hline Mean & 0.26 & -0.55 & -1.36 & -2.25 & -0.97 & -1.35 \\
\hline SD & 1.11 & 2.77 & 1.83 & 2.72 & 2.13 & 2.72 \\
\hline LOCF $(\mathrm{kg}) \mathrm{N}$ & 27 & 27 & 27 & 27 & 27 & 27 \\
\hline Mean & 0.19 & -0.41 & -0.90 & -1.55 & -0.82 & -1.20 \\
\hline SD & 0.93 & 2.38 & 1.62 & 2.43 & 1.99 & 2.52 \\
\hline ITT $(\mathrm{kg}) \mathrm{N}$ & 27 & 27 & 27 & 27 & 27 & 27 \\
\hline Mean & 0.32 & -0.17 & -0.75 & -1.20 & -0.76 & -0.93 \\
\hline SD & 0.93 & 2.45 & 1.72 & 2.67 & 2.02 & 2.60 \\
\hline
\end{tabular}

LOCF $=$ Last Observation Carried Forward

$I T=$ Intent to Treat 
Table 3 Means (SD) for Leptin

\begin{tabular}{|c|c|c|c|c|}
\hline Leptin* (pg/ml) & & Baseline & 6-weeks & 12-weeks \\
\hline & No Vegetable Juice & $\begin{array}{r}2.93 \times 10^{4} \\
\left(1.99 \times 10^{4}\right)\end{array}$ & $\begin{array}{c}3.07 \times 10^{4} \\
\left(2.30 \times 10^{4}\right)\end{array}$ & $\begin{array}{r}3.57 \times 10^{4} \\
\left(3.09 \times 10^{4}\right)\end{array}$ \\
\hline & 8 fluid ounces Vegetable Juice & $\begin{array}{c}4.30 \times 10^{4} \\
\left(1.81 \times 10^{4}\right)\end{array}$ & $\begin{array}{c}3.51 \times 10^{4} \\
\left(1.33 \times 10^{4}\right)\end{array}$ & $\begin{array}{r}3.16 \times 10^{4} \\
\left(1.12 \times 10^{4}\right)\end{array}$ \\
\hline & 16 fluid ounces Vegetable Juice & $\begin{array}{c}3.87 \times 10^{4} \\
\left(2.99 \times 10^{4}\right)\end{array}$ & $\begin{array}{c}4.47 \times 10^{4} \\
\left(2.85 \times 10^{4}\right)\end{array}$ & $\begin{array}{c}4.27 \times 10^{4} \\
\left(2.97 \times 10^{4}\right)\end{array}$ \\
\hline
\end{tabular}

${ }^{*} \mathrm{p}$-value $=0.01$ for overall repeated measures model interaction among treatment and change from baseline to 12 weeks.

observed over time or group by time interactions with regard to usual vegetable intake.

\section{Metabolic Syndrome}

Based on group assignment, there was a significant difference in the percent of subjects who met the metabolic syndrome criterion of elevated triglycerides at the end of the 12 week study, (Chi-square $=7.9 ; \mathrm{p}=0.02$ ) with $40.0 \%$ still meeting the criterion in the no juice control group, while $5.6 \%$ and $13.6 \%$ met the criterion in the 8 fluid ounce/day and 16 fluid ounce/day juice groups respectively. A follow-up logistic model with the juice groups aggregated (comparing any vegetable juice consumption to none) and adjusting for age, education, and gender was developed to predict meeting the elevated triglyceride criterion at 12 weeks. This model demonstrated that those drinking the vegetable juice $(10.0 \%)$ were less likely $(\mathrm{OR}=0.91 ; \mathrm{p}=0.01)$ to meet the triglyceride criterion for metabolic syndrome than those not receiving the juice (40.0\%). The overall model was statistically significant (Chi-square $=19.5 ; \mathrm{p}=$ 0.003). There were no significant differences among groups with any of the other metabolic syndrome criteria.

\section{Discussion}

Diets rich in vegetables and fruits have been shown to help individuals reach and achieve a healthy weight [5] and improve cardiovascular disease risk $[7,40]$. This positive result has been attributed to the fact that vegetables and fruit are typically low in calories and have been shown to increase satiation $[6,41]$. However, adopting and maintaining a healthy lifestyle that includes a diet rich in vegetables, fruits, lean meats and low fat dairy products, is problematic for many individuals [8]. The current study examined whether including an easily accessible, portable vegetable-based beverage as part of a calorie-controlled DASH diet could increase vegetable intake and improve clinical characteristics of the metabolic syndrome in a group of individuals with a mean age of 49.8 years, predominately female (73\%), with $84 \%$ self-identified as African American, Mexican American or other minority. During the 12 week study, participants received two individual counseling sessions with registered dietitians (at baseline and 6 weeks). Although everyone was counseled on a calorie-controlled DASH diet only those who were instructed to also incorporate 8 and 16 fluid ounces of vegetable juice per day significantly increased their vegetable consumption and significantly reduced their carbohydrate intake. Regardless of whether vegetable servings included or excluded the "starchy vegetables" (such as those defined by the Diabetic Vegetable Exchanges [42]), subjects consumed significantly more vegetables in the juice treatment groups.

This dietary practice translated to a significant amount of weight loss in the vegetable juice groups compared to those who did not incorporate the vegetable juice into the DASH diet. The amount of weight lost was modest, approximately $0.33 \mathrm{lb}$ per week. But, this positive, "small-step" change is thought to be successful [43] and in our intervention resulted in a significantly greater weight loss over the 12 weeks in the group that incorporated vegetable juice into the DASH diet compared to the group that did not drink the juice.

Individuals with metabolic syndrome are at higher risk for both diabetes and atherosclerotic cardiovascular disease. Weight reduction is known to improve risk factors associated with metabolic syndrome $[44,45]$. In the current study, after 12 weeks of vegetable juice consumption, the modest reduction in weight $(<5 \%$ for most subjects), translated to a lower percentage of subjects that met the metabolic syndrome criteria for high triglycerides (i.e. $>150 \mathrm{mg} / \mathrm{dl}$ ). No significant changes were observed in any of the other measured metabolic or cardiovascular risk factors. However, we did observe a significant decrease in plasma leptin. Leptin is synthesized and secreted from adipocytes and is highly correlated with energy storage in adipose tissue $[46,47]$. Analogous to our results, the observation that changes in leptin and triglycerides parallel weight loss, regardless of mechanism to reduce weight, has been observed by other investigators $[48,49]$.

It is important to note that the DASH diet instructions emphasized including vegetables of all forms in their daily diets, but only those groups provided with the simple intervention of adding vegetable juice significantly increasing vegetable intake. According to subjects' responses on the Beverage Consumption questionnaires, 
Table 4 Food Record Data: Completers Juice Data Included

\begin{tabular}{|c|c|c|c|}
\hline \multirow{2}{*}{$\begin{array}{l}\text { Nutrient } \\
\text { Mean (SD) }\end{array}$} & \multicolumn{3}{|c|}{ Measurement Point } \\
\hline & Baseline & 6 Weeks & 12 Weeks \\
\hline \multicolumn{4}{|l|}{ Total Calories } \\
\hline No Vegetable Juice & $1898.5(599.9)$ & $1986.7(687.6)$ & $1865.9(667.3)$ \\
\hline 8 fluid ounces Vegetable Juice & 2015.9 (931.9) & $1672.6(1146.7)$ & $1654.7(571.6)$ \\
\hline 16 fluid ounces Vegetable Juice & $2184.0(703.6)$ & $2030.1(984.4)$ & $1676.7(429.7)$ \\
\hline \multicolumn{4}{|l|}{ Percent of Calories from Fat } \\
\hline No Vegetable Juice & $37.5(7.4)$ & $31.7(14.1)$ & $33.8(7.5)$ \\
\hline 8 fluid ounces Vegetable Juice & $39.3(7.8)$ & $33.9(16.2)$ & $29.7(9.5)$ \\
\hline 16 fluid ounces Vegetable Juice & $35.8(7.4)$ & $27.9(13.4)$ & $32.4(9.7)$ \\
\hline \multicolumn{4}{|l|}{ Protein Intake (g) } \\
\hline No Vegetable Juice & $84.2(29.1)$ & $89.8(36.4)$ & $78.2(30.3)$ \\
\hline 8 fluid ounces Vegetable Juice & $79.6(27.2)$ & $74.3(35.1)$ & $63.5(16.1)$ \\
\hline 16 fluid ounces Vegetable Juice & $95.6(36.6)$ & $91.2(37.1)$ & $76.4(19.2)$ \\
\hline \multicolumn{4}{|l|}{ Carbohydrate Intake (g) } \\
\hline No Vegetable Juice & $209.9(60.0)$ & $244.0(100.7)$ & $234.3(103.3)$ \\
\hline 8 fluid ounces Vegetable Juice & $224.2(106.4)$ & $195.2(64.5)$ & $220.3(73.5)$ \\
\hline 16 fluid ounces Vegetable Juice & $256.2(96.1)$ & $219.3(80.5)$ & $205.4(75.7)$ \\
\hline \multicolumn{4}{|l|}{ Fat Intake (g) } \\
\hline No Vegetable Juice & $80.8(37.4)$ & $68.8(37.0)$ & $70.3(30.5)$ \\
\hline 8 fluid ounces Vegetable Juice & $90.6(55.3)$ & $54.5(31.8)$ & $58.3(34.0)$ \\
\hline 16 fluid ounces Vegetable Juice & $86.3(32.8)$ & $56.6(24.2)$ & $61.8(29.0)$ \\
\hline \multicolumn{4}{|l|}{ Vitamin A Carotenoid (RE) } \\
\hline No Vegetable Juice & $157.0(191.4)$ & $541.4(826.6)$ & $424.7(544.1)$ \\
\hline 8 fluid ounces Vegetable Juice & $514.6(557.2)$ & $601.3(788.6)$ & $491.6(628.0)$ \\
\hline 16 fluid ounces Vegetable Juice & $218.0(264.7)$ & $403.8(479.1)$ & $485.5(528.1)$ \\
\hline \multicolumn{4}{|l|}{ Vitamin $C^{*}(\mathrm{mg})$} \\
\hline No Vegetable Juice & $65.9(77.9)$ & $69.3(45.6)$ & $97.8(76.5)$ \\
\hline 8 fluid ounces Vegetable Juice & $88.8(64.5)$ & $132.5(30.1)$ & $146.1(50.2)$ \\
\hline 16 fluid ounces Vegetable Juice & $63.5(44.1)$ & 236.8(108.4) & $240.7(91.5)$ \\
\hline \multicolumn{4}{|l|}{ Sodium (mg) } \\
\hline No Vegetable Juice & $3589.7(1372.2)$ & $3386.2(1213.2)$ & $3775.2(1572.8)$ \\
\hline 8 fluid ounces Vegetable Juice & $3274.5(1492.2)$ & $2699.2(1273.4)$ & $2707.6(1133.3)$ \\
\hline 16 fluid ounces Vegetable Juice & $4283.0(3843.3)$ & $2697.6(959.2)$ & $2995.7(1100.5)$ \\
\hline \multicolumn{4}{|l|}{ Potassium* (mg) } \\
\hline No Vegetable Juice & $1784.3(777.4)$ & $1954.8(892.7)$ & $1695.0(675.5)$ \\
\hline 8 fluid ounces Vegetable Juice & $2004.1(824.9)$ & $2391.3(645.8)$ & $2496.0(776.2)$ \\
\hline 16 fluid ounces Vegetable Juice & $2057.1(1029.0)$ & $3170.0(868.2)$ & $3341.4(822.8)$ \\
\hline \multicolumn{4}{|l|}{ Fiber (g) } \\
\hline No Vegetable Juice & $17.5(8.1)$ & 18.0(8.4) & 19.3(9.4) \\
\hline 8 fluid ounces Vegetable Juice & 20.6(12.2) & 19.2(8.4) & $16.9(5.3)$ \\
\hline 16 fluid ounces Vegetable Juice & 16.8(8.6) & $20.5(10.3)$ & 18.6(7.3) \\
\hline
\end{tabular}

${ }^{*} \mathrm{p}$-value $<0.05$ for overall repeated measures model interaction among treatment and change from baseline to 12 weeks.

the juice was an acceptable addition to their diets. Apart from the vegetable juice, our subjects would not have met vegetable recommendations. Many different population groups do not meet current vegetable recommendations [50-52]. Inadequate vegetable intake is a widespread issue [53]. Although campaigns promoting vegetables and fruits, such as the 5-A-Day program, have been publicized in the media and the public recognizes them [54], there is disconnect between the recommendations and typical consumption $[6,50,51,55]$. In agreement with the above, in the current study, despite our DASH diet education, including an emphasis on vegetable intake, we observed no increases in dietary vegetables, apart from the added vegetable juice over time. 
Table 5 Vegetable Intake from the Food Records Including and Excluding V8 Consumption

\begin{tabular}{lccc}
\hline \multicolumn{4}{c}{ Including Vegetable Juice } \\
\hline & Baseline & 6 Weeks & 12 Weeks \\
\hline MyPyramid Vegetables* & $\mathrm{N}=54$ & $\mathrm{~N}=46$ & $\mathrm{~N}=53$ \\
\hline No Vegetable Juice & $1.2(0.9)$ & $1.7(1.3)$ & $1.7(1.3)$ \\
\hline 8 fluid ounces Vegetable Juice & $1.9(1.1)$ & $2.5(1.0)$ & $2.9(1.5)$ \\
\hline 16 fluid ounces Vegetable Juice & $1.3(0.8)$ & $3.0(1.1)$ & $3.4(1.0)$ \\
\hline \multicolumn{4}{c}{ Excluding Vegetable Juice } \\
\hline MyPyramid Vegetables & $\mathrm{N}=54$ & $\mathrm{~N}=46$ & $\mathrm{~N}=53$ \\
\hline No Vegetable Juice & $1.2(0.9)$ & $1.7(1.3)$ & $1.7(1.3)$ \\
\hline 8 fluid ounces Vegetable Juice & $1.9(1.1)$ & $1.5(1.0)$ & $2.0(1.5)$ \\
\hline 16 fluid ounces Vegetable Juice & $1.3(0.8)$ & $1.3(0.9)$ & $1.6(0.9)$ \\
\hline
\end{tabular}

${ }^{*}$ p-value $<0.01$ for overall repeated measures model interaction among treatment and change from baseline to 12 weeks.

Education alone typically does not seem to relate to significant dietary improvements. McGee et al. studied a population with similar education to the present study, with approximately half of the participants with a high school education or less, and found that barriers to change towards a more healthful diet included lack of knowledge and skills [9]. Despite the fact that we provided our subjects with DASH diet knowledge and food preparation tips, our participants still did not meet their vegetable recommendations unless a vegetable juice beverage was provided to them. Although a serious disease may motivate changes in dietary behavior, our subjects had cardiovascular risk factors, rather than a major cardiovascular event, which may have reduced their incentive to follow DASH diet guidelines [9]. For example, Campbell et al. found that in a predominantly female population, consisting of a high percentage of minorities, it was possible to increase knowledge of infant feeding through education but that knowledge alone did not elicit change in dietary behaviors [56]. Dietary interventions and education targeting minorities is especially difficult $[57,58]$. However, our study showed beneficial dietary changes in minorities. Participants provided a vegetable beverage greatly enhanced their vegetable consumption, something the DASH counseling and materials alone, were unable to achieve. Consistent with the current study, Weerts et al. [59] reported that African American women, given nutritional and behavioral education, were more likely to increase their consumption of vegetables and consequently lose weight when they were provided with gift cards that were explicitly for vegetables and fruits.

While studies have observed blood pressure reductions in trials incorporating tomato based products $[21,22]$, we did not. These studies used tomato-based extracts, rather than a tomato-based juice. In addition to a lack of effect on blood pressure, vegetable juice consumption also did not correlate to an improvement in oxidative stress parameters, although a significant increase in vitamin $C$ intake was observed in the vegetable juice groups. We note that other markers of antioxidant and oxidative stress may have yielded different results [60].

Limitations of the current study design include its short duration of 12 weeks. A longer study could provide data on weight loss maintenance, a key factor for weight control and health. In addition, since attrition was slightly higher than anticipated, even though it was not significantly different among groups, it became necessary to aggregate the groups consuming the vegetable juice for statistical power. While examination of the variables using the LOCF and ITT models did not reach statistical significance, they do show the same basic trends as the aggregated models. When looking at the more conservative models combined with the aggregated model, we acknowledge that our findings are preliminary and more research is needed. Another limitation to our study was the relatively modest-to-low rate of adherence among the 16 fluid ounces/day group. There were no significant differences in the adjusted models for weight loss among all three groups, however, on average, those who consumed 16 fluid ounces/day lost less weight than those who consumed 8 fluid ounces/day. It is difficult to know why the 16 fluid ounces/day group may not have been as effective as the 8 fluid ounces/day group in terms of weight loss. One possibility is the relatively low adherence to the intervention protocol in those assigned to consume a greater volume of juice. This finding indicates that it may be difficult, in a clinical or public health setting to recommend drinking 16 fluid ounces/day of vegetable juice.

\section{Conclusion}

In conclusion our study demonstrates that the incorporation of vegetable juice is a simple and effective way to help meet vegetable recommendations and improve Vitamin $C$ and potassium intake. Data from this study also suggest the potential of using a low sodium vegetable juice in conjunction with a calorie restricted diet to aid in weight loss in overweight individuals with metabolic syndrome.

\section{Acknowledgements}

This work was supported by resources from the Campbell Soup Company. We thank Kerri Green, Veronica Holley, Etta Reynolds and Sarah Lane Liscum for technical support, undergraduate student assistants for database entry, and all the participants from this study.

\section{Author details}

${ }^{1}$ Department of Nutrition, University of California, Davis, USA. ${ }^{2}$ Institute for Biobehavioral Health Research, National Development and Research Institutes (NDRI), Leawood, Kansas, USA. ${ }^{3}$ Department of Medicine, Baylor College of Medicine, Houston, Texas, USA. ${ }^{4}$ Department of Nutrition and 
Exercise Science, Bastyr University, Kenmore, Washington, USA. ${ }^{5}$ Department of Internal Medicine, University of California, Davis, USA. ${ }^{6}$ Campbell Soup Company, Camden, New Jersey, USA.

\section{Authors' contributions}

SFS interpreted data, drafted and critically reviewed the manuscript, and gave final approval of the version to be published. WSCP analyzed and interpreted data, drafted and critically reviewed manuscript and gave final approval of the version to be published. RSR acquired and interpreted data, drafted and critically reviewed manuscript, and gave final approval of the version to be published. AGK interpreted data, drafted and critically reviewed the manuscript, and gave final approval of the version to be published. RRH made substantial contributions to conception and design of study, acquired and interpreted data, drafted and critically reviewed the manuscript, and gave final approval of the version to be published. CLK made substantial contributions to conception and design of study, interpreted data, drafted and critically reviewed the manuscript, and gave final approval of the version to be published. HJC acquired data, drafted and critically reviewed the manuscript, and gave final approval of the version to be published. CKH analyzed and interpreted data, drafted and critically reviewed manuscript and gave final approval of the version to be published. BLW made substantial contributions to conception and design of study, interpreted data, drafted and critically reviewed the manuscript, and gave final approval of the version to be published. CSK made substantial contributions to conception and design of study, interpreted data, drafted and critically reviewed the manuscript, and gave final approval of the version to be published. JPF made substantial contributions to conception and design of study, interpreted data, drafted and critically reviewed the manuscript, and gave final approval of the version to be published.

\section{Competing interests}

This work was supported by resources from the Campbell Soup Company. CS Khoo and BL Winters are employees of Campbell Soup Company and hold stock there. CL Keen and JP Foreyt are members of Campbell Soup Company's Vegetable Plant Advisory Panel. SF Shenoy, WSC Poston, RS Reeves, AG Kazaks, RR Holt, HJ Chen, CK Haddock do not have any financial interests to declare.

\section{Received: 19 November 2009}

Accepted: 23 February 2010 Published: 23 February 2010

\section{References}

1. Despres JP, Lemieux I: Abdominal obesity and metabolic syndrome. Nature 2006, 444(7121):881-887.

2. Schneider JG, Tompkins C, Blumenthal RS, Mora S: The metabolic syndrome in women. Cardiol Rev 2006, 14(6):286-291.

3. Ervin BR: Prevalence of Metabolic Syndrome Among Adults 20 Years of Age and Over, by Sex, Age, Race and Ethnicity, and Body Mass Index: United States, 2003-2006. National Health Statistics Reports 2009, 1-8.

4. Foreyt JP: The role of lifestyle modification in dysmetabolic syndrome management. Nestle Nutr Workshop Ser Clin Perform Programme 2006, 11:197-205, discussion 205-196.

5. Ledikwe JH, Blanck HM, Kettel Khan L, Serdula MK, Seymour JD, Tohill BC, Rolls BJ: Dietary energy density is associated with energy intake and weight status in US adults. Am J Clin Nutr 2006, 83(6):1362-1368.

6. Fruit and vegetable consumption among adults-United States, 2005. MMWR Morb Mortal Wkly Rep 2007, 56(10):213-217.

7. He FJ, Nowson CA, Lucas M, MacGregor GA: Increased consumption of fruit and vegetables is related to a reduced risk of coronary heart disease: meta-analysis of cohort studies. J Hum Hypertens 2007, 21(9):717-728.

8. Bianchi C, Penno G, Daniele G, Benzi L, Del Prato S, Miccoli R: Optimizing management of metabolic syndrome to reduce risk: focus on life-style. Intern Emerg Med 2008, 3(2):87-98.

9. McGee BB, Richardson V, Johnson GS, Thornton A, Johnson C, Yadrick K, Ndirangu M, Goolsby S, Watkins D, Simpson PM, et al: Perceptions of factors influencing healthful food consumption behavior in the Lower Mississippi Delta: focus group findings. Journal of nutrition education and behavior 2008, 40(2):102-109.

10. Vitolins MZ, Quandt SA, Bell RA, Arcury TA, Case LD: Quality of diets consumed by older rural adults. J Rural Health 2002, 18(1):49-56.
11. John JH, Ziebland S: Reported barriers to eating more fruit and vegetables before and after participation in a randomized controlled trial: a qualitative study. Health Educ Res 2004, 19(2):165-174.

12. James DC, Rienzo BA, Frazee C: Using focus group interviews to understand school meal choices. J Sch Health 1996, 66(4):128-131.

13. Anderson AS, Cox DN, McKellar S, Reynolds J, Lean ME, Mela DJ: Take Five, a nutrition education intervention to increase fruit and vegetable intakes: impact on attitudes towards dietary change. Br J Nutr 1998, 80(2):133-140.

14. Heber D: Vegetables, fruits and phytoestrogens in the prevention of diseases. J Postgrad Med 2004, 50(2):145-149.

15. Azadbakht L, Mirmiran P, Azizi F: Dietary diversity score is favorably associated with the metabolic syndrome in Tehranian adults. Int $J$ Obes (Lond) 2005, 29(11):1361-1367.

16. Esmaillzadeh A, Kimiagar M, Mehrabi Y, Azadbakht L, Hu FB, Willett WC: Fruit and vegetable intakes, C-reactive protein, and the metabolic syndrome. Am J Clin Nutr 2006, 84(6):1489-1497.

17. Esposito K, Ciotola M, Giugliano D: Mediterranean diet and the metabolic syndrome. Mol Nutr Food Res 2007, 51(10):1268-1274.

18. Feldeisen SE, Tucker KL: Nutritional strategies in the prevention and treatment of metabolic syndrome. Appl Physiol Nutr Metab 2007, 32(1):46-60

19. Il'yasova D, Ivanova A, Morrow JD, Cesari M, Pahor M: Correlation between two markers of inflammation, serum C-reactive protein and interleukin 6 , and indices of oxidative stress in patients with high risk of cardiovascular disease. Biomarkers 2008, 13(1):41-51.

20. Dwyer JH, Paul-Labrador MJ, Fan J, Shircore AM, Merz CN, Dwyer KM: Progression of carotid intima-media thickness and plasma antioxidants: the Los Angeles Atherosclerosis Study. Arterioscler Thromb Vasc Biol 2004, 24(2):313-319

21. Engelhard YN, Gazer B, Paran E: Natural antioxidants from tomato extract reduce blood pressure in patients with grade- 1 hypertension: a doubleblind, placebo-controlled pilot study. Am Heart J 2006, 151(1):100.

22. Paran $E$, Novack $V$, Engelhard $Y N$, Hazan-Halevy l: The effects of natural antioxidants from tomato extract in treated but uncontrolled hypertensive patients. Cardiovasc Drugs Ther 2009, 23(2):145-151.

23. O'Kennedy N, Crosbie L, van Lieshout M, Broom JI, Webb DJ, Duttaroy AK: Effects of antiplatelet components of tomato extract on platelet function in vitro and ex vivo: a time-course cannulation study in healthy humans. Am J Clin Nutr 2006, 84(3):570-579.

24. O'Kennedy N, Crosbie L, Whelan S, Luther V, Horgan G, Broom Jl, Webb DJ, Duttaroy AK: Effects of tomato extract on platelet function: a doubleblinded crossover study in healthy humans. Am J Clin Nutr 2006, 84(3):561-569.

25. McCarty MF: Proposal for a dietary "phytochemical index". Med Hypotheses 2004, 63(5):813-817.

26. Balzer J, Rassaf $T$, Heiss $C$, Kleinbongard $P$, Lauer $T$, Merx M, Heussen $N$, Gross $H B$, Keen $C L$, Schroeter $H$, et al: Sustained benefits in vascular function through flavanol-containing cocoa in medicated diabetic patients a double-masked, randomized, controlled trial. J Am Coll Cardiol 2008, 51(22):2141-2149.

27. McQuillan BM, Hung J, Beilby JP, Nidorf M, Thompson PL: Antioxidant vitamins and the risk of carotid atherosclerosis. The Perth Carotid Ultrasound Disease Assessment study (CUDAS). J Am Coll Cardiol 2001, 38(7):1788-1794.

28. Dietary guidelines for Americans, 2005. US Department of Health and Human Services, US Department of Agriculture, 62005

29. Your Guide to Lowering Your blood Pressure with DASH. NIH Publication No. 06-4082: US Department of Health and Human Services 2006.

30. Conway SP, Pond MN, Hamnett T, Watson A: Compliance with treatment in adult patients with cystic fibrosis. Thorax 1996, 51(1):29-33.

31. Cortet B, Benichou O: Adherence, persistence, concordance: do we provide optimal management to our patients with osteoporosis?. Joint Bone Spine 2006, 73(5):e1-7.

32. Inside the Pyramid-What foods are in the vegetable group?. US Department of Health and Human Services, US Department of Agriculture 2005.

33. Wang JF, Schramm DD, Holt RR, Ensunsa JL, Fraga CG, Schmitz HH, Keen $\mathrm{CL}$ : A dose-response effect from chocolate consumption on plasma epicatechin and oxidative damage. J Nutr 2000, 130(8S Suppl):2115S-2119S. 
34. Pi-Sunyer FX, Aronne LJ, Heshmati HM, Devin J, Rosenstock J: Effect of rimonabant, a cannabinoid-1 receptor blocker, on weight and cardiometabolic risk factors in overweight or obese patients: RIO-North America: a randomized controlled trial. JAMA 2006, 295(7):761-775.

35. Wadden TA, Berkowitz RI, Womble LG, Sarwer DB, Phelan S, Cato RK, Hesson LA, Osei SY, Kaplan R, Stunkard AJ: Randomized trial of lifestyle modification and pharmacotherapy for obesity. N Engl J Med 2005, 353(20):2111-2120.

36. Poston WS, Haddock CK, Pinkston MM, Pace P, Reeves RS, Karakoc N, Jones $P$, Foreyt JP: Evaluation of a primary care-oriented brief counselling intervention for obesity with and without orlistat. J Intern Med 2006, 260(4):388-398.

37. Jelalian E, Hart CN, Mehlenbeck RS, Lloyd-Richardson EE, Kaplan JD, FlynnO'Brien KT, Wing RR: Predictors of attrition and weight loss in an adolescent weight control program. Obesity (Silver Spring) 2008, 16(6):1318-1323.

38. Rowe JL, Downey JE, Faust M, Horn MJ: Psychological and demographic predictors of successful weight loss following silastic ring vertical stapled gastroplasty. Psychol Rep 2000, 86(3 Pt 1):1028-1036.

39. Teixeira PJ, Going SB, Sardinha LB, Lohman TG: A review of psychosocial pre-treatment predictors of weight control. Obes Rev 2005, 6(1):43-65.

40. Nikolic M, Nikic D, Petrovic B: Fruit and vegetable intake and the risk for developing coronary heart disease. Cent Eur J Public Health 2008, 16(1):17-20.

41. Rolls BJ, Ello-Martin JA, Tohill BC: What can intervention studies tell us about the relationship between fruit and vegetable consumption and weight management?. Nutr Rev 2004, 62(1):1-17.

42. Wheeler ML: Nutrient database for the 2003 exchange lists for meal planning. J Am Diet Assoc 2003, 103(7):894-920.

43. Catenacci VA, Wyatt HR: America on the move. Med Clin North Am 2007, 91(6):1079-1089, viii.

44. Brook RD, Bard RL, Glazewski L, Kehrer C, Bodary PF, Eitzman DL, Rajagopalan S: Effect of short-term weight loss on the metabolic syndrome and conduit vascular endothelial function in overweight adults. Am J Cardiol 2004, 93(8):1012-1016.

45. Grundy SM: Cardiovascular and metabolic risk factors: how can we improve outcomes in the high-risk patient?. Am J Med 2007, 120(9 Suppl 1):S3-8.

46. Bluher $S$, Mantzoros CS: Leptin in humans: lessons from translational research. Am J Clin Nutr 2009, 89(3):991S-997S.

47. Considine RV, Sinha MK, Heiman ML, Kriauciunas A, Stephens TW, Nyce MR, Ohannesian JP, Marco CC, McKee LJ, Bauer TL, et al: Serum immunoreactive-leptin concentrations in normal-weight and obese humans. N Engl J Med 1996, 334(5):292-295.

48. Goodpaster BH, Kelley DE, Wing RR, Meier A, Thaete FL: Effects of weight loss on regional fat distribution and insulin sensitivity in obesity. Diabetes 1999, 48(4):839-847.

49. Xydakis AM, Case CC, Jones PH, Hoogeveen RC, Liu MY, Smith EO, Nelson KW, Ballantyne CM: Adiponectin, inflammation, and the expression of the metabolic syndrome in obese individuals: the impact of rapid weight loss through caloric restriction. J Clin Endocrinol Metab 2004, 89(6):2697-2703.

50. Blanck HM, Gillespie C, Kimmons JE, Seymour JD, Serdula MK: Trends in fruit and vegetable consumption among U.S. men and women, 19942005. Prev Chronic Dis 2008, 5(2):A35.

51. Guenther PM, Dodd KW, Reedy J, Krebs-Smith SM: Most Americans eat much less than recommended amounts of fruits and vegetables. J Am Diet Assoc 2006, 106(9):1371-1379.

52. Kimmons J, Gillespie C, Seymour J, Serdula M, Blanck HM: Fruit and vegetable intake among adolescents and adults in the United States: percentage meeting individualized recommendations. Medscape J Med 2009, 11(1):26

53. Hall JN, Moore S, Harper SB, Lynch JW: Global variability in fruit and vegetable consumption. Am J Prev Med 2009, 36(5):402-409, e405.

54. Ashfield-Watt PA: Fruits and vegetables, 5+ a day: are we getting the message across?. Asia Pac J Clin Nutr 2006, 15(2):245-252.

55. Prevalence of fruit and vegetable consumption and physical activity by race/ethnicity-United States, 2005. MMWR Morb Mortal Wkly Rep 2007, 56(13):301-304.

56. Campbell MK, Carbone E, Honess-Morreale L, Heisler-Mackinnon J, Demissie S, Farrell D: Randomized trial of a tailored nutrition education
CD-ROM program for women receiving food assistance. Journal of nutrition education and behavior 2004, 36(2):58-66.

57. Kristal AR, Feng Z, Coates RJ, Oberman A, George V: Associations of race/ ethnicity, education, and dietary intervention with the validity and reliability of a food frequency questionnaire: the Women's Health Trial Feasibility Study in Minority Populations. Am J Epidemiol 1997, 146(10):856-869.

58. Thomas J: Nutrition intervention in ethnic minority groups. Proc Nutr Soc 2002, 61(4):559-567.

59. Weerts SE, Amoran A: Pass the Fruits and Vegetables! A CommunityUniversity-Industry Partnership Promotes Weight Loss in African American Women. Health Promot Pract 2009.

60. Frankel EN, Finley JW: How to standardize the multiplicity of methods to evaluate natural antioxidants. J Agric Food Chem 2008, 56(13):4901-4908.

\section{doi:10.1186/1475-2891-9-8}

Cite this article as: Shenoy et al:: Weight loss in individuals with metabolic syndrome given DASH diet counseling when provided a low sodium vegetable juice: a randomized controlled trial. Nutrition Journal 2010 9:8.

\section{Submit your next manuscript to BioMed Central and take full advantage of:}

- Convenient online submission

- Thorough peer review

- No space constraints or color figure charges

- Immediate publication on acceptance

- Inclusion in PubMed, CAS, Scopus and Google Scholar

- Research which is freely available for redistribution
C Biomed Central 